\title{
Secretory Processes in Follicular Cells of the Thyroid Gland of the Indian Sheath-tailed Bat, Taphozous longimanus (Hardwicke): A Ultrastructural Study
}

\author{
Archana A. Nerkar* and Mohan M. Gadegone \\ Cell Biology Section, Department of Zoology, Institute of Science, R. T. Road, Civil Lines, \\ Nagpur 440001, India
}

Received April 6, 2010; accepted March 3, 2011

\begin{abstract}
Summary The aim of present study was to compare the ultrastructural changes in thyroid gland during different phases of the reproductive cycle of Taphozous longimanus. Thyroid gland shows marked seasonal variation in weight, quantity of colloid and follicular epithelial height and ultrastructural characteristics. During estrus, the thyroid gland is composed of small and medium follicles. The follicular cells contain mitochondria with lamellar cristae, well developed rough endoplasmic reticulum and Golgi complex and large number of dense bodies. During early and midpregnancy, thyroid gland composed mostly of small follicles. The characteristics of the follicular cells are the well developed rough endoplasmic reticulum, Golgi apparatus and numerous dense granules. Colloid droplets are observed in the cytoplasm. These findings are associated with a high rate of thyroid activity. Towards the end of pregnancy, the large follicles are noticed in the thyroid gland in addition to medium sized follicles. The follicular cells of large follicles contain inconspicuous Golgi apparatus, a few mitochondria and rudimentary rough endoplasmic reticulum, suggesting a low rate of thyroid activity. During lactation, the thyroid gland as in estrus is composed of medium to small sized follicles. The ultrastructural features of thyroid follicular cells indicate that these cells are synthetically very active.
\end{abstract}

Key words Ultrastructure, Bat, Thyroid gland, Follicles, Reproductive cycle.

The thyroid gland plays a crucial role in growth, development and metabolism of nearly all the tissues (Boswell et al. 1994). Apart from the regulating the basal metabolic rate, thyroid plays an important role in the maintenance, growth and reproduction. Both hyper- and hypothyroidism are believed to be closely associated with sterility, infertility and abortion (Mayant 1964, Jannini et al 1995, Kwiecinski and Damassa 2000).

Among bats, the thyroid gland was studied mainly in the temperate zone bats that undergo prolonged hibernation (Sadler and Tyler 1960 a, b, Azzali 1964, Velicky and Titlbach 1972, 1974, Burns et al. 1972, Ifuta et al. 1988). Thyroid function in these bats, as in other mammals and hibernators, exhibits marked seasonal variations.

Cyclical changes in the structure of the thyroid gland in Indian bats are reported in $T$. longimanus at Varanasi, India (Singh et al 2002) and Hipposideros lankadiva (Seraphim 2004) during different phases of the reproductive cycle. The secretory processes in the follicular cells of thyroid of bats at ultrasructural level were studied during various phases of hibernation in bats (Nunez and Becker 1970, Nunez 1971, Fujita 1971 and Nunez et al. 1974).

Although Chiropterans are the second largest order of mammals, detailed reproductive patterns and their associated endocrine characteristic have been documented in only a few species. The detailed reproductive patterns have been described in the emballonurid bat, T. longimanus from India (Gopalakrishna 1955, Krishna and Dominic 1982a). T. longimanus shows geographic

\footnotetext{
*Corresponding author, e-mail: archana_nerkar1@yahoo.co.in
} 
variation in the reproductive patterns. In Varanasi, India, T. longimanus shows a seasonally dioestrus pattern (Krishna and Dominic 1982 a) while in Nagpur, Central India exhibits an aseasonal polyestrus (continuous) breeding pattern (Gopalakrishna 1955). The endocrine characteristics of the anomalous reproductive pattern of $T$. longimanus have not yet been studied. The present electron microscopic study was undertaken with a view to study the ultrastructural changes in thyroid gland of $T$. longimanus during the reproductive cycle.

\section{Materials and methods}

The emballonurid bat, T. longimanus (Hardwicke), was selected for the present study because of its unique reproductive habits. The specimens were collected from Nagpur, throughout the year, representing different reproductive states. The specimens were brought to the laboratory alive. Mature females were separated from immature females after observing mammary glands and pelvic dugs.

For electron microscopic studies, thyroid glands were immediately removed from non pregnant and pregnant bats after they were killed by decapitation. The tissues were fixed in fresh ice-cold 3\% glutaraldehyde for $3 \mathrm{~h}$ and then $4 \mathrm{~h}$ in $0.1 \mathrm{M}$ cacodylate buffer. The tissues were washed in buffer and then post fixed for 1 to $2 \mathrm{~h}$ in $1 \% 0.067 \mathrm{M}$ cacodylate-buffered osmium tetroxide. After dehydration with graded series of alcohol, the tissues were cleared in propylene oxide solution and embedded in Araldite resin which would be polymerized at $60^{\circ} \mathrm{C}$. Then, ultrathin sections from selected blocks were cut with glass knife and picked up on 400-mesh copper grids. Sections were double stained with $10 \%$ alcoholic uranyl acetate for $20 \mathrm{~min}$ and for $10 \mathrm{~min}$ in Reynold's lead citrate. The sections were examined under a JEM Jeol-100s electron microscope (Japan) at 80KU accelerating voltage and photographed.

\section{Observations}

Thyroid gland of T. longimanus is composed of 2 different kinds of parenchymal cells, parafollicular cells (C-cells or calcitonin secretory cells) and follicular epithelial cells.

The thyroid gland during estrus shows heterogenous population of follicles. It is composed of small to medium sized follicles. The follicular cells of active follicles exhibit morphological characteristics suggestive of high synthetic activity (Fig. 1). The thyroid follicles are lined by high cuboidal epithelial cells and their lumina are filled with electron dense colloid material. The nucleus is round to oval, placed towards the basal region of cytoplasm. The nucleus contains condensed chromatin materials, scattered in the nucleoplasm and also clumped at the periphery and a single nucleolus is observed in each nucleus. Nuclear pores are visible. The cytoplasmic matrix is finely granular and considerably dense. The most distinctive ultrastructural feature of follicular cells of estrus bats is the well developed endoplasmic reticulum, well developed Golgi zone and abundant mitochondria. The endoplasmic reticulum and mitochondria are closely associated with each other.

The profiles of rough surfaced endoplasmic reticulum are seen scattered throughout the cytoplasm. Rough endoplasmic reticulum is in the form of dilated tubular cisternae and also in the form of dilated round cisternae are observed. In some cells, round to ovoid, small to medium sized polymorphic profiles of endoplasmic reticulum are observed. The degree of dilation of cisternae of rough endoplasmic reticulum varies with the cell. All cisternae of rough endoplasmic reticulum are heavily dotted with ribosomes and filled with low electron dense material. Free ribosomes are seen scattered in the cytoplasmic matrix.

Mitochondria are scattered throughout the cytoplasm. They are associated with rough endoplasmic reticulum. They are ovoid to elongate in shape. Mitochondrial cristae are prominently 


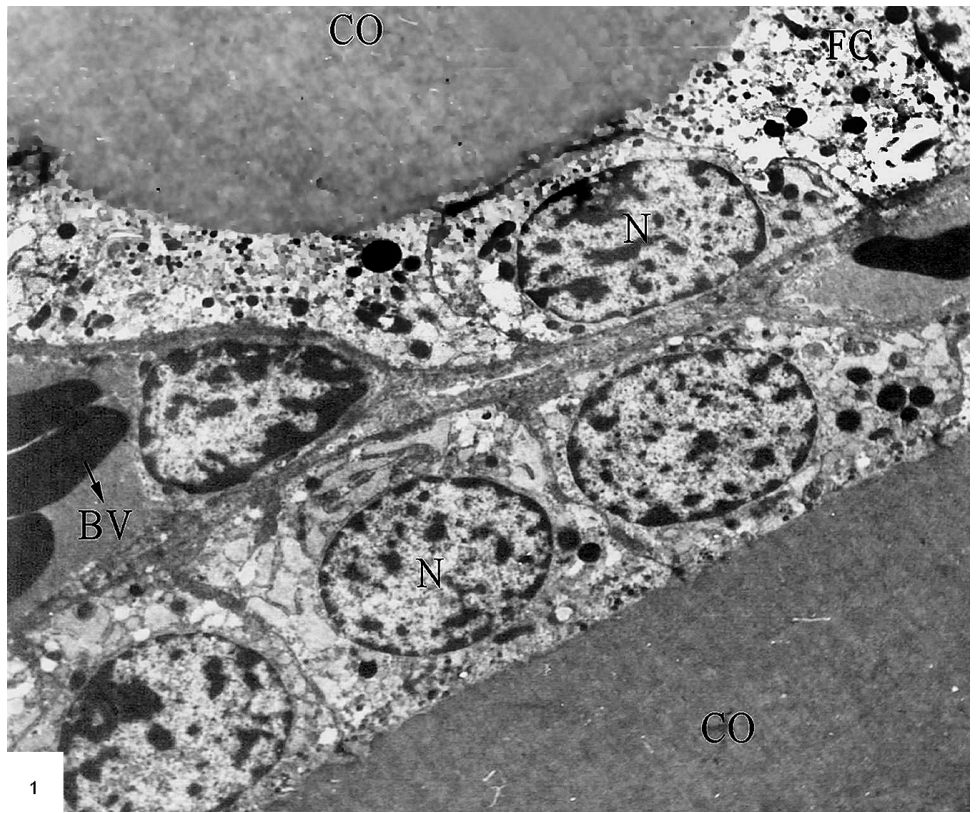

Fig. 1. Electron micrograph of thyroid follicles during estrus. The active follicles are lined by low columnar epithelial cells and lumen is filled with electron dense homogenous colloid material. Note the blood vessel in the interfollicular area. $\times 8000$

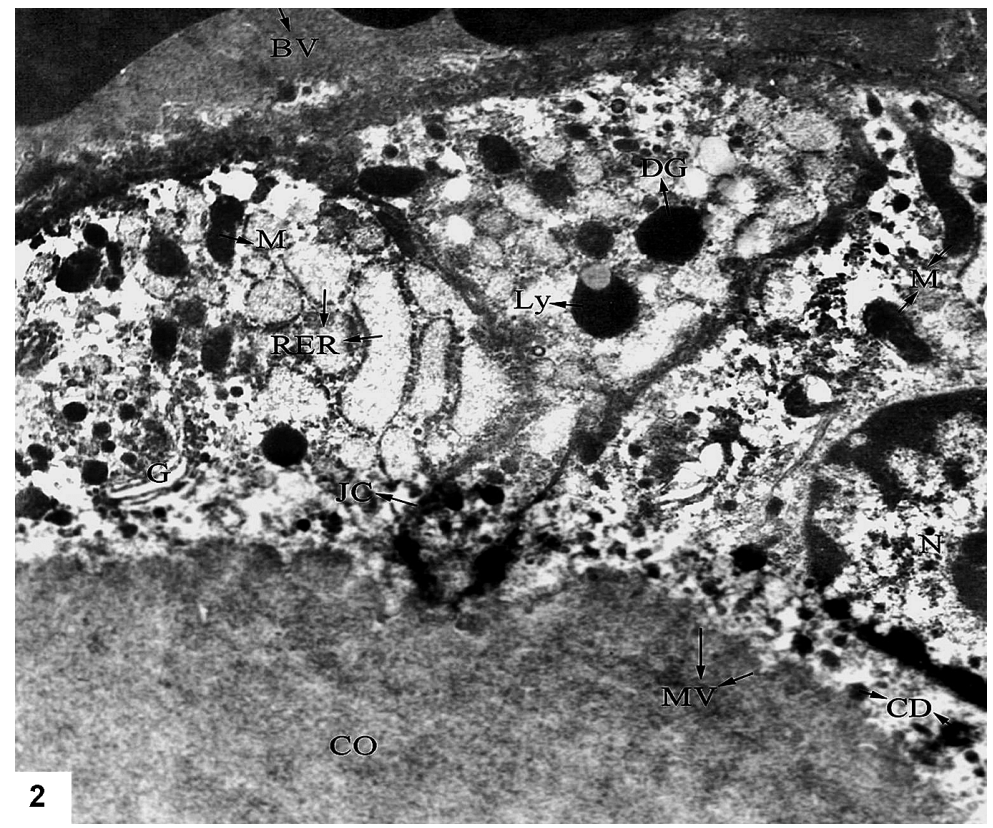

Fig. 2. Electron micrograph of follicular cell during estrus showing nucleus $(\mathrm{N})$ with condensed chromatin materials. Colloid material is of moderate electron density. Apical microvilli (MV) which are very short and blunt and apical plasma membrane exhibits small enfolding. Note the presence of apical junctional complexes (JC), several ovoid to elongated mitochondria (M) with lamellar cristae, lysosome (Ly), and dense bodies and well developed Golgi complex (G). Dilated cisternae of rough endoplasmic reticulum (RER) in the form of round to elongated profiles are seen throughout the cytoplasm. Large blood vessel is observed near the basal lamina. $\times 12000$ 
lamellar with electron dense matrix. The Golgi zone is present in the apical cytoplasm. Golgi complex is greater in complexity and size. Outer zone of complex is made up of elongated flattened to dilated profiles arranged in an almost circular manner while inner zone consists of dilated, irregular, saccules with associated vesicles containing homogenous material of high electron density. The coated vesicles are also observed near the saccules. Lysosomal bodies are observed in the cytoplasm.

Many round to ovoid membrane bound bodies containing material nearly identical in texture to the luminal colloid designated as colloid droplets are observed in the apical and middle region of the cytoplasm. The follicular cells possess microvilli which are very short and spaced at irregular intervals along the apical cell surface. In many cells apical plasma membrane exhibits small infolding. The lateral boundaries exhibit apical junctional complexes which run a relatively straight course from apex to the base with occasional infolding. Desmosomes are observed between 2 adjacent cells. Dense granules are ovoid or irregular in shape are seen in the middle region of the cytoplasm. Majority of dense granules contain homogenous matrix of moderately fine granularity. One or 2 vacuolated dense bodies are seen in the cytoplasm (Figs. 2-4).

In contrast to estrus, thyroid during early and mid-pregnancy consists of mostly small sized follicles. The active thyroid follicles are lined by low columnar to high cuboid epithelium. Nucleus is oval to elongate in shape with 1 or 2 nucleoli. The nucleus shows condensed chromatin material along the nuclear membrane. Nuclear pores are visible (Fig. 5). As in the follicular cells of estrus bat, the follicular cells of pregnant bat also contain Golgi apparatus (Fig. 6). It is made up of dilated saccules associated with small vesicles. All cisternae of rough endoplasmic reticulum are dilated and they show various shapes and sizes and are heavily dotted with ribosomes. Mitochondria are oval to rod shaped with lamellar cristae. Some mitochondria are vacuolated. Apical cell surface is

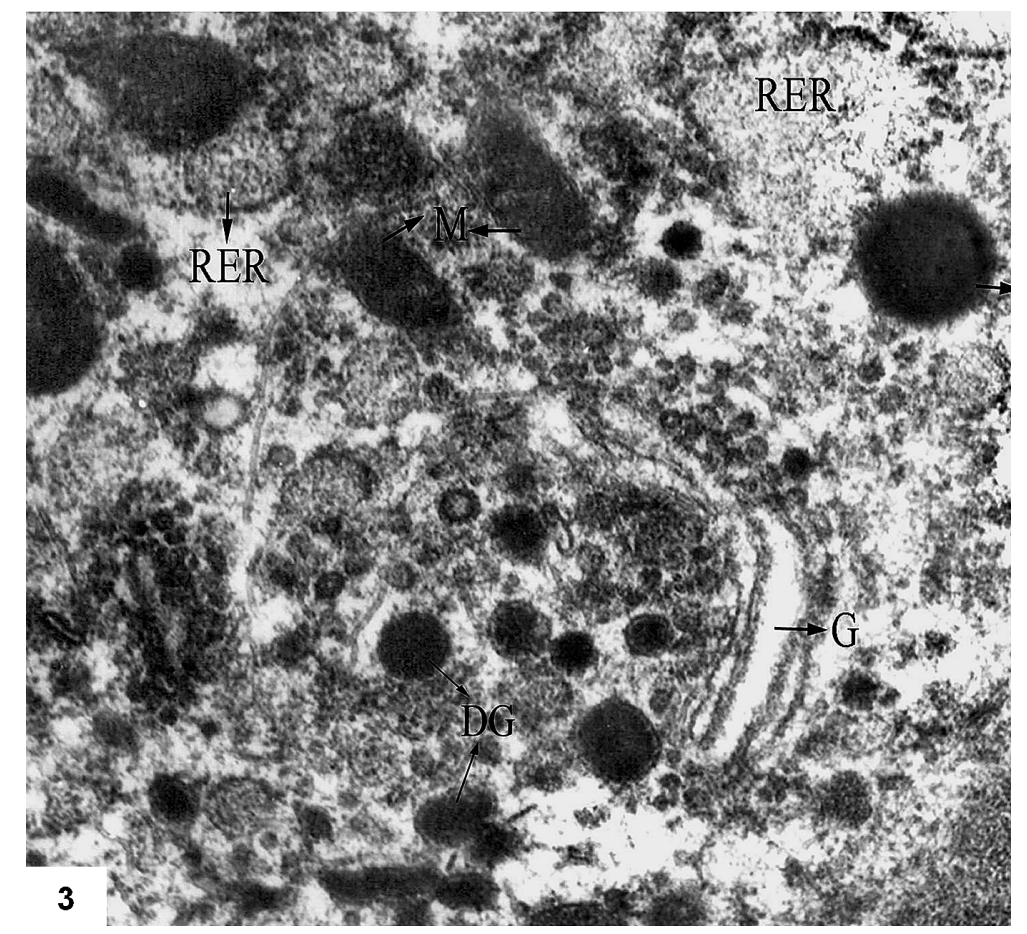

Fig. 3. Electron micrograph of part of the follicular cell showing dilated cisternae of rough endoplasmic reticulum (RER), numerous dense bodies (DB), round to elongated mitochondria (M) and well developed Golgi complex (G). Golgi cisternae are dilated with small coated vesicles. $\times 10000$ 


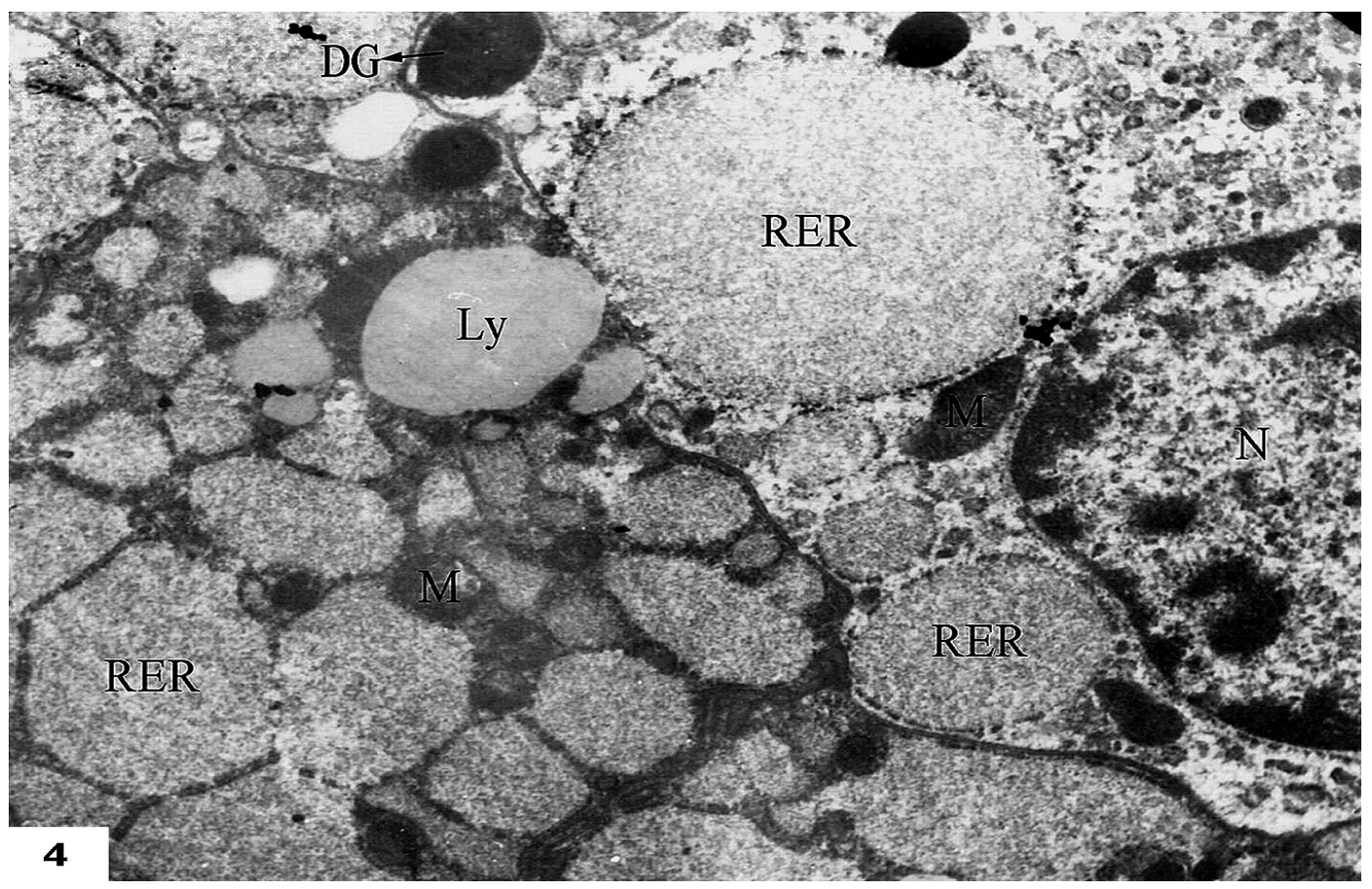

Fig. 4. Electron micrograph of follicular cell during estrus showing nucleus (N), lysosome (Ly) and a few round to elongated mitochondria $(\mathrm{M})$. Note several round to polymorphic profiles of rough endoplasmic reticulum (RER) with varying degree of dilation of cisternae of rough endoplasmic reticulum. $\times 10000$

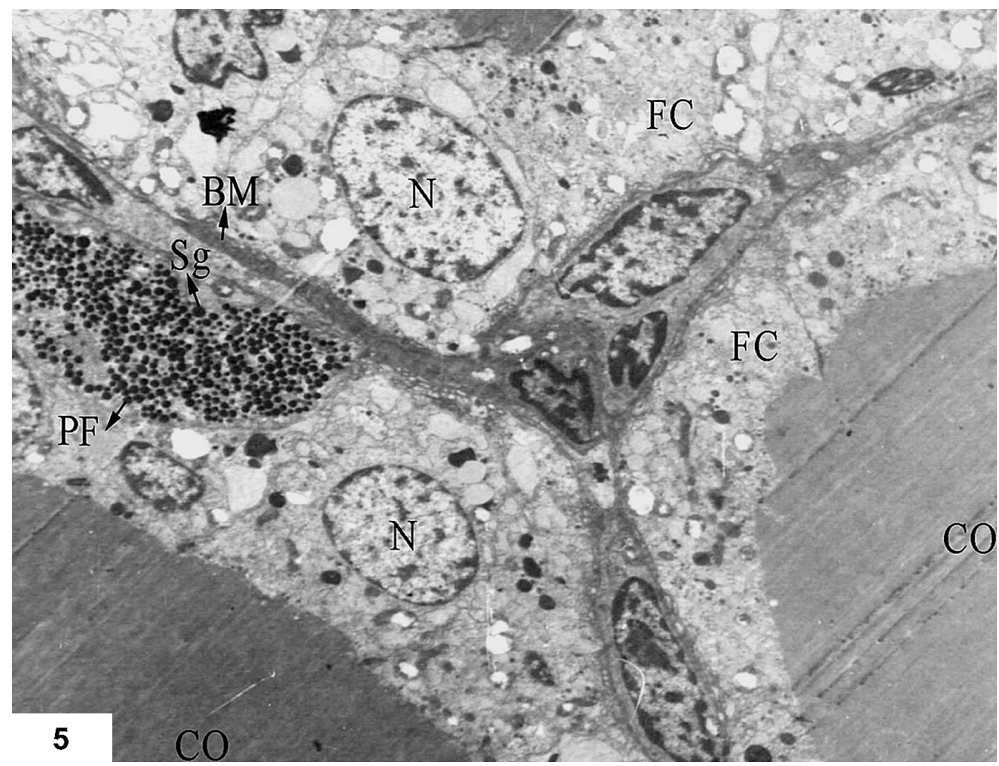

Fig. 5. Electron micrograph of thyroid gland during mid-pregnancy showing active follicles lined by cuboidal to low columnar cells. Lumina are filled with electron dense colloid material. Note the presence of parafollicular cell at the base of the follicular cell. $\times 8000$ 


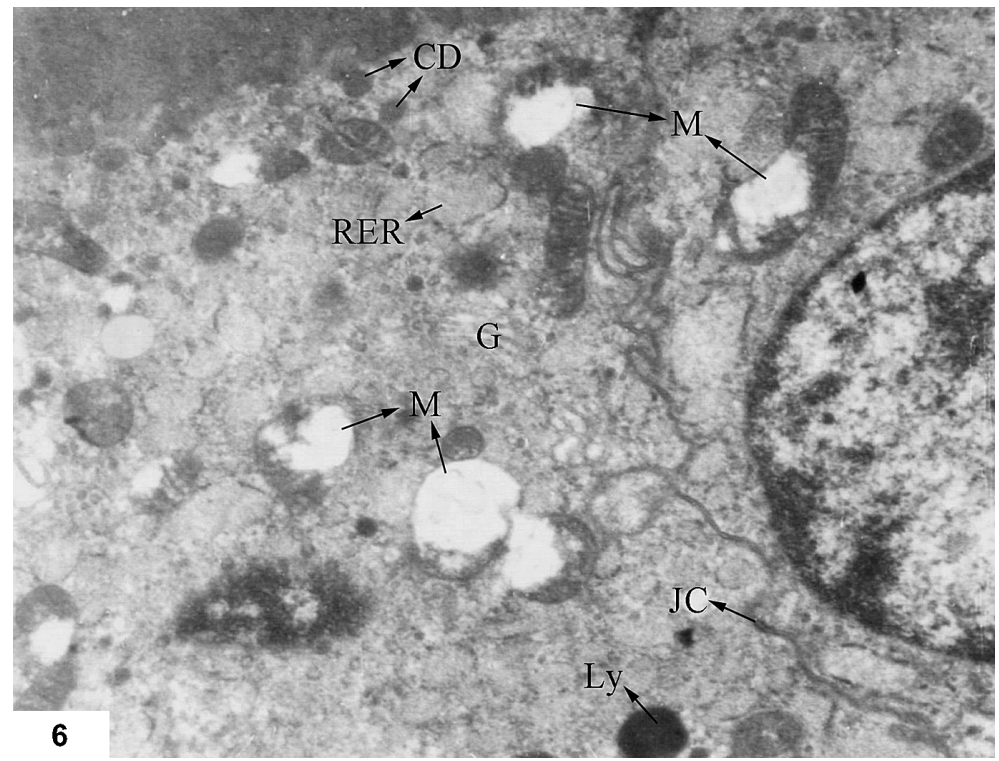

Fig. 6. Electron micrograph of follicular cell during mid- pregnancy showing nucleus $(\mathrm{N})$ with chromatin clumps, electron dense colloid material in the lumen of the follicle. Note the dilated cisternae of roughed endoplasmic reticulum (RER), Golgi apparatus (G), lysosome (Ly) and oval to elongated mitochondria (M) with lamellar or collapsed cristae. The lateral plasma membrane shows inter digitations and junctional complexes (JC) are also seen. $\times 10000$

punctuated by small irregularly spaced microvilli. Follicular lumina are filled with colloid material of moderate electron density. Intracytoplasmic membrane limited granules or colloid droplets are observed in the apical cytoplasm. A large lipid droplet is noticed in the cytoplasm. Cytoplasmic dense granules vary in size and shape. Numerous vacuolated dense granules vary in size and shapes are observed scattered in the cytoplasm (Fig. 7).

During late pregnancy, thyroid gland consists of large and medium sized follicles. These large sized follicles are lined by low cuboidal to squamous epithelium. These follicles show degenerating characters. A large number of clear vacuoles of various shapes and sizes are observed in the cytoplasm. Follicular lumen is filled with electron dense material.

Mitochondria with lamellar or collapsed cristae are observed. Golgi and rough endoplasmic reticulum are not clearly defined. Lateral cell boundaries of the follicular cells show apical junctional complexes and interdigitations of lateral plasma membrane. Vacuolated dense bodies are observed in the cytoplasm. The morphological characteristics of follicular cells of large follicles are synthetically inactive during late pregnancy (Fig. 8).

The thyroid gland of the lactating females shows medium and small sized follicles. During lactation, the fine structure of follicular cells changes again. The lumina of the follicles are filled with colloid material of moderate electron density. The active thyroid follicles are lined by cuboidal to low columner epithelium.

The follicular cells show distended profiles of endoplasmic reticulum. Many large, round to ovoid profiles of rough endoplasmic reticulum are observed. Some cells, rough endoplasmic reticulum appeared as elongated profiles. These cisternae of rough endoplasmic reticulum are nearly dotted with ribosomes enclosing homogenous material. Free ribosomes are numerous.

Few mitochondria are seen in apical cytoplasm. They are closely opposed to elements of the endoplasmic reticulum. Mitochondria are oval to elongated and also curved with lamellar cristae. Some mitochondria show collapsed cristae. Golgi complex is inconspicuous. The apical junctional 
complexes and the specialized junctions between parafollicular cells and follicular cells are observed as in estrus. The follicular cells show interdigitations between the adjacent cells. Large numbers of membrane limited structures called dense bodies are observed in the cytoplasm of cells. Small and medium vacuolated dense bodies are also seen in the apical cytoplasm. Some dense

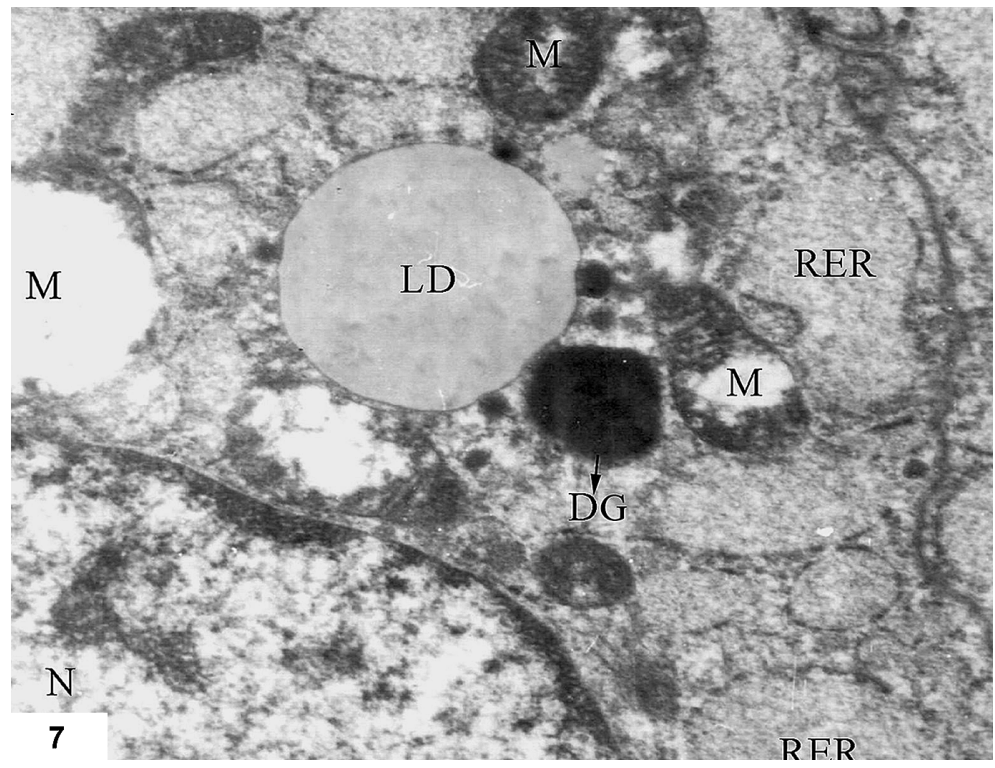

Fig. 7. Electron micrograph of thyroid gland during late pregnancy showing large follicle (degenerating) lined by squamous to cuboidal epithelium. Follicular lumina are filled with electron lucent homogenous colloid material (CO). The cytoplasm is vacuolated and reduced Golgi (G), mitochondria (M) and rough endoplasmic reticulum (RER). Note the blood vessel (BV) in the follicular area. $\times 8000$

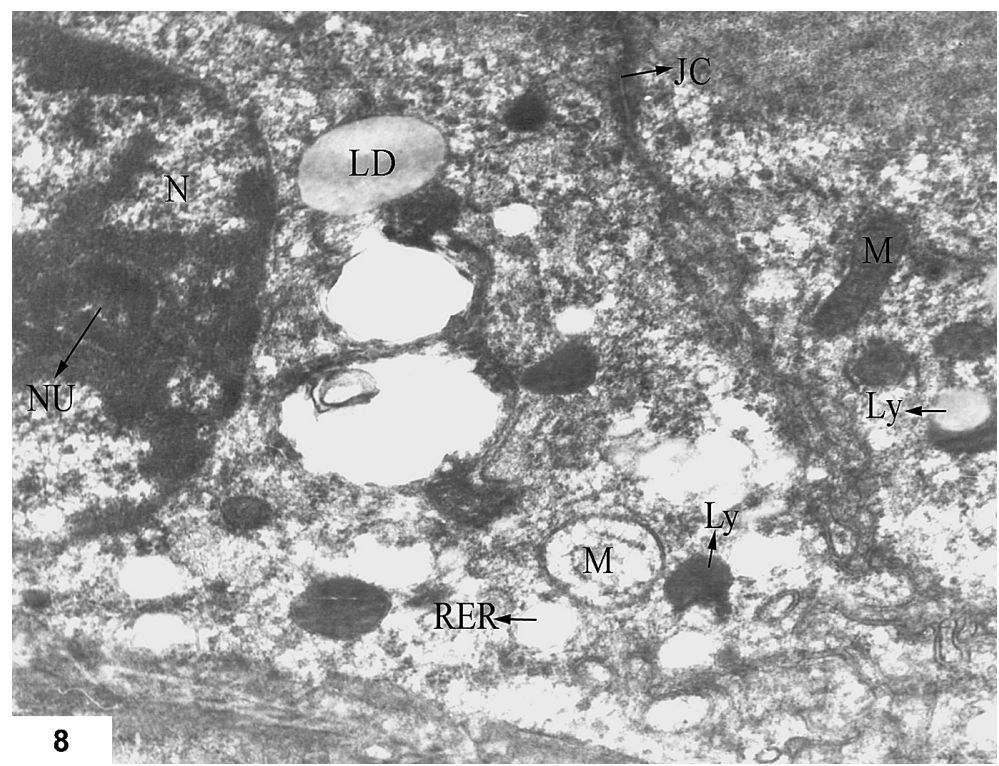

Fig. 8. Electron micrograph of follicular cell during late pregnancy showing nucleus $(\mathrm{N})$, some oval to rod shaped mitochondria (M) with lamellar cristae, numerous vacuolated bodies, lysosome (Ly) and junctional complex (JC) along the lateral plasma membrane. The poorly developed Golgi $(\mathrm{G})$ and rough endoplasmic reticulum $(\mathrm{RER}) . \times 10000$ 


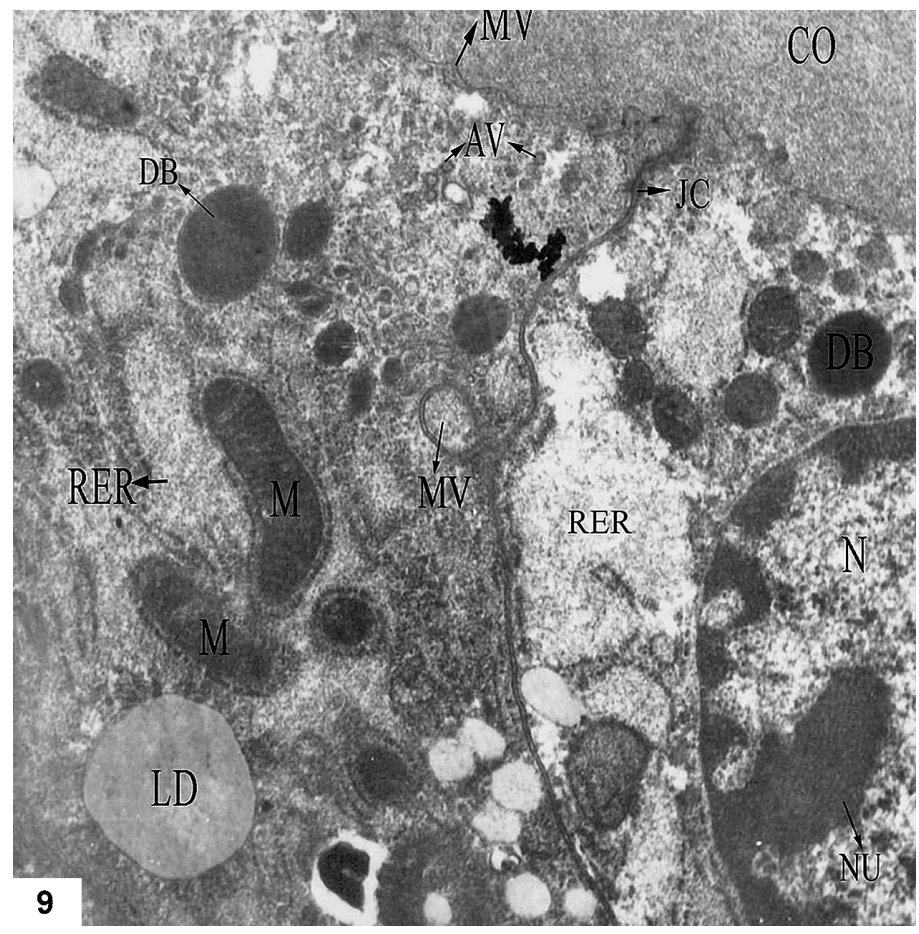

Fig. 9. Electron micrograph of follicular cell of the thyroid gland during lactation showing the oval nucleus (N) with nucleolus, several dilated cisternae of rough endoplasmic reticulum (RER) and many oval to elongated mitochondria (M) with lamellar cristae which are closely associated with rough endoplasmic reticulum. Note lipid droplets (LD) and several cytoplasmic dense bodies (DB) are found in the apical regions of the cell, some blunt microvilli (MV) arising from apical plasma membrane protruding into the lumen of follicle which is filled with electron dense colloid (CO), apical junctional complexes (JC) and a few small apical vesicles (AV) beneath the plasma membrane are also observed. $\times 12000$

granules contain vacuoles or dark areas within their matrix. A lipid droplet and 1 or 2 lysosomal bodies are observed in the cytoplasm. Microvilli are blunt and sparsely distributed. Beneath the plasma membrane a few small apical vacuoles are observed. Colloid droplets are seen in the apical cytoplasm (Figs. 9, 10).

\section{Discussion}

In Taphozous, the thyroid follicles, colloid and epithelial cell height show significant variation during the reproductive cycle. During estrus and lactation, thyroid gland show heterogenous population of follicles. However, during pregnancy, the thyroid gland is composed of homogenous population of follicles. At the end of gestation, large follicles are observed at the periphery of gland. Singh et al. (2002) reported seasonal variation in structure of thyroid gland of T. longimanus at Varanasi, India. The species shows seasonally dioestrus breeding pattern. During quiescence, thyroid follicles are homogenous in appearance while during recrudescence and breeding it shows heterogenous population of follicles. During pregnancy (post breeding period) thyroid is made up of small to large sized follicles indicating high thyroid activity, supporting present observations.

The thyroid gland of $T$. longimanus shows small to medium size and large follicles during different phases of sexual cycle. The large follicles are lined by low cuboidal to squamous epithelial cells indicating low synthetic activity, while small follicles are lined by low columnar to high 


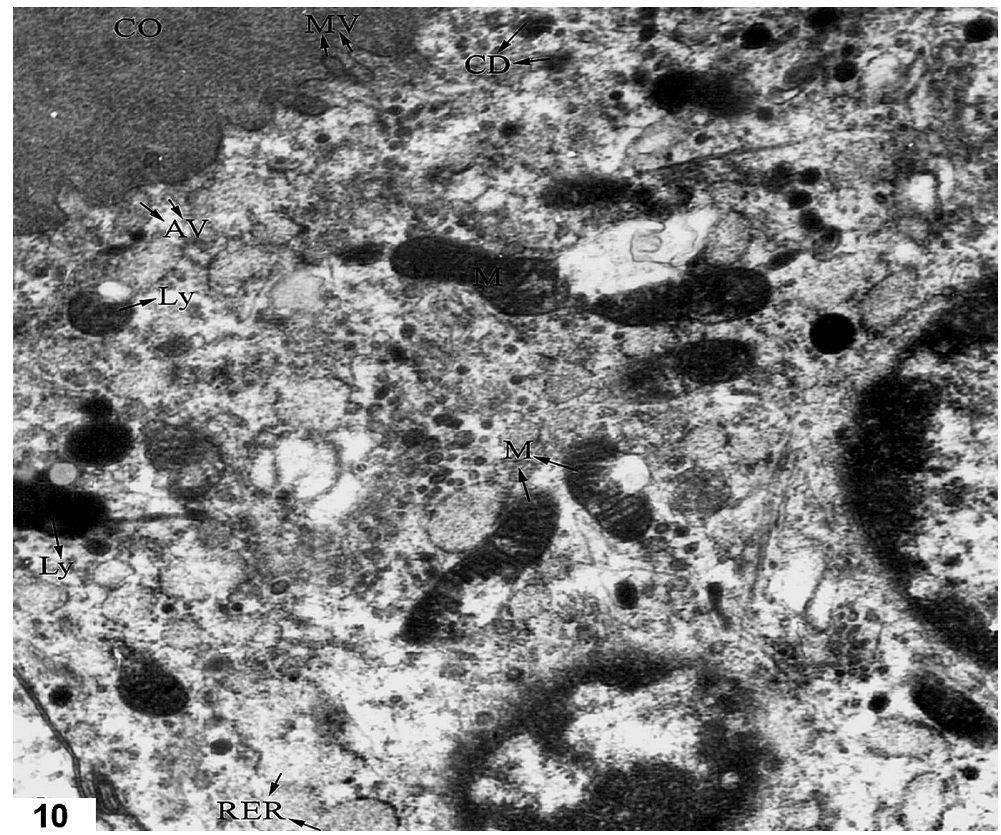

Fig. 10. Electron micrograph of follicular cell during lactation showing nucleus $(\mathrm{N})$ and oval to elongated mitochondria (M) with lamellar cristae. Note several blunt microvilli (MV) are seen arising from the apical plasma membrane protruding into the lumen. Dilated cisternae of rough endoplasmic reticulum (RER), lysosomal bodies (Ly) and a few small apical vesicles (AV) just beneath the plasma membrane are observed in cytoplasmic matrix. Lateral plasma membrane shows interdigitations. $\times 12000$

cuboidal cells indicating increased synthetic activity. Similar observations are reported in hibernating and nonhibernating species of bats (Singh et al. 2002, Nunez et al. 1971, 1974, Kwiecinski et al. 1987b, Loewenstein and Wollman 1967, Seraphim 2004) during their reproductive cycle.

The most distinctive ultrastructural features in follicular cells of estrus thyroid of $T$. longimanus are mitochondria with lamellar cristae which are closely apposed to the elements of the rough surfaced endoplasmic reticulum. Many small to medium sized polymorphic profiles of rough endoplasmic reticulum are distributed throughout the cytoplasm. A well developed Golgi zone is seen in the cytoplasm. A large number of dense bodies, vacuolated dense bodies and lysosomal bodies and lipid droplets are observed in the cytoplasm.

Seasonal variation in the morphology of the thyroid gland has been studied in many mammals (Krupp et al. 1977, Atoji et al. 1999, Shimokawa et al. 2002, Abdel-Magied et al. 2000). They reported similar ultrastructural features of thyroid gland as in T. longimanus supporting present observations. Ultrastructural changes in follicular cells of the bat thyroid during various phases of hibernation were studied (Nunez and Becker 1970, Fujita 1971, Nunez et al. 1970, 1974).

In H. lankadiva (Seraphim 2004), thyroid gland is active during estrus similar to that reported in Taphozous. The ultrastructure of follicular cells of estrus bat, H. lankadiva shows the presence of dilated rough endoplasmic reticulum, well developed Golgi apparatus, mitochondria with lamellar cristae and apical blebs towards the luminal plasma membrane. These ultrastructural features of thyroid follicular cells of estrus bat indicate that these cells are synthetically active and elaborate large quantities of thyroid hormones.

The ultrastrucutural features of follicular cells of $T$. longimanus during early and midpregnancy show the presence of Golgi apparatus and hypertrophied mitochondria with lamellar 
cristae. The cisternae of rough endoplasmic reticulum are dilated and the degree of dilation varies with the cells. These dilated cisternae are dotted with ribosomes and contain homogenous material of moderate electron density. One or 2 dense bodies, a lipid droplets and absence of lysosomes are observed in the cytoplasm.

H. lankadiva is nonhibernating bat showing embryonic diapause during early pregnancy. Thyroid follicles are lined by flattened epithelium. The cytoplasm is vacuolated. Cell organelles are not well developed suggesting a reserve or storage phase of the cells indicating maternal hypothyroidism during embryonic diapause.

The large follicles lined by flattened epithelium and homogenous colloid in the lumen during embryonic diapause were recorded in nonhibernating bat, M. californicus (Burns et al. 1972). The large follicles with the low cuboidal cells represent the reserve state of colloid. The synthetic activity is lowered down. The colloidal materials in the lumina of follicles are simply used up indicating maternal hypothyroidism. During pregnancy the animal is in great stress, so to overcome the stress the utilization of the colloid is more.

T. longimanus is a nonhibernating bat and does not show embryonic diapause, the thyroid gland is very active during early and mid gestation, contradicting the results of Seraphim (2004). However in hibernating bat, the follicular cells of thyroid gland during the early stages of arousal are highly active. The cell contains a well developed endoplasmic reticulum and an extensive Golgi complex along with many large colloid droplets and numerous dense granules. These ultrastructural changes in follicular cells may reflect preparation by the thyroid for arousal from hibernation (Nunez et al. 1974). Similar observations are reported during estrus and early pregnancy of $T$. longimanus.

During late pregnancy, large follicles are observed in thyroid gland. The follicular cells contain mitochondria with lamellar or collapsed cristae. Follicular lumen is filled with electron dense material. Golgi and rough endoplasmic reticulum are not clearly defined. The follicular cells of large follicles are synthetically inactive during late pregnancy. Similar observations are reported in thyroid glands of camels during summer (Abdel-Magied et al. 2000) and in wood chuck, Marmota monax during winter (Krupp et al. 1977).

According to Fakuda et al. (1980), the secretory activity of thyroid gland decreases at full term in rats. Khurana and Madan (1986) observed the decrease in thyroid activity at the late pregnancy in heifers and in M. lucifugus (Kwiecinski et al. 1991). The bat thyroid gland during mid and late hibernation (Dec. to early April) have shown that follicular cells decline in the height contain small Golgi complex, relatively few mitochondria and a rudimentary rough endoplasmic reticulum (Nunez and Becker 1970, Nunez 1971). These findings are associated with a low rate of thyroid activity. Similar results were obtained in thyroid gland of late pregnant bat of T. longimanus.

Thyroid gland of lactating bats shows active follicles. The ultrastructural features of follicular cells indicate that these cells actively elaborate the thyroid hormones during lactation. The ultrastructural changes in the thyroid follicular cells of $H$. lankadiva are similar to this observed in the thyroid follicular cells of T. longimanus during pregnancy and lactation (Seraphim 2004). Similar ultrastructural changes in follicular cells are also observed in thyroid gland of pre-arousal bat (Nunez et al. 1974).

When bat prepares to enter hibernation, large numbers of lysosomal structures are produced by follicular cells. These appeared to be involved in autophagy, removing cell organelles not required during hibernation (Nunez and Becker 1970). Autophagic vacuoles are not observed in prearoused bat. Therefore, large number of dense granules in these animals may reflect intracellular accumulation and storage of primary lysosomes. These lysosomal materials may be used at arousal of bats (Nunez et al. 1974). In T. longimanus during estrus, large numbers of membrane limited structures called dense bodies which are similar to lysosomes are observed in the cytoplasm of cells. Small and medium vacuolated dense bodies are also seen in the apical cytoplasm. They 
represent degenerated dense granules. Some dense granules contain vacuoles or dark areas within their matrix. These lysosomal bodies in follicular cells of $T$. longimanus may be used for removal of excess of secretory material not needed during estrus.

The follicular cells of thyroid gland of pregnant and non-pregnant adult bats of Taphozous contain well developed endoplasmic reticulum, well developed Golgi apparatus with small vesicles and numerous mitochondria with lamellar cristae. The endoplasmic reticulum is closely associated with mitochondria. Many colloid droplets, dense granules and apical vesicles observed in the cytoplasm. These organelles are indicative of synthesis of thyroglobulin in endoplasmic reticulum, packaged in to small vesicles in the Golgi complex, and transported via Golgi derived vesicles to the cell surface before being discharged into the follicular lumen. Fabrication of thyroid hormones may be conducted by the enzyme thyroid peroxidase, in the apical plasma membrane of thyroid epithelial cells, as suggested in other mammals (Nunez et al. 1974, Krupp et al. 1977, AbdelMagied et al. 2000)

Many large round to ovoid membrane limited structures called as colloid droplets are observed in the cytoplasm of follicular cells of Taphozous during estrus and pregnancy. These colloid droplets are associated with dense granules containing enzymes. The fusion of colloid droplets with dense granules may bring about hydrolysis of colloid with the subsequent release of thyroxine and triiodothyroxine. As blood capillaries are observed below the basal lamina of the thyroid follicular cells in the Taphozous, free thyroid hormones may be diffusing through the basal plasma membrane into blood, where they quickly bind to carrier protein for transport to target cells, regulating cellular oxidation and metabolism (Seljelid 1967, Wollman 1969).

In T. longimanus the lateral cell boundaries exhibit apical junctional complexes which run straight course from the apex of the cell towards its base. The specialized junctions such as gap junctions and desmosomes are observed between parafollicular cells and follicular cells. The follicular cells show interdigitations between the adjacent cells. In bats $M$. lucifugus and $P$. pipistrellus, desmosomes are frequent, seen along the lateral plasma membrane and an unusual type of cell to cell contact between adjacent follicular cells (Nunez 1971). The iodine concentrating functions of thyroid follicular cells occurred at the basal membrane rather than at the lateral membrane where organelle associated junctions are found (Wollman 1969). The intercellular junctions provide a site for trans cellular exchange or transport of iodide, other ions or both (Brightman and Reese 1969). Similar function may be attributed to the junctional complexes present in the follicular cells of thyroid gland of the T. longimanus.

The serum $\mathrm{T}_{3}$ and $\mathrm{T}_{4}$ concentration showed significant variation with changes in reproductive cycle of bat, T. longimanus which shows bimodal pregnancy at Varanasi, India (Singh et. al. 2002). A peak of $T_{3}$ and $T_{4}$ was noticed during breeding in late winter in January and at the time of mating and implantation. In the present study, we did not measure the plasma concentration of $\mathrm{T}_{3}$ and $\mathrm{T}_{4}$ during the reproductive cycle. Thyroid follicular cells are active during mating and implantation and elaborate thyroid hormones as indicated by ultrastructural features such as well developed rough endoplasmic reticulum, numerous mitochondria, well developed Golgi apparatus and colloid droplets in the follicular cells. The $\mathrm{T}_{3}$ and $\mathrm{T}_{4}$ concentration declined during the period of delayed embryonic development (Feb.-March) in the first pregnancy. In the present study thyroid follicles are synthetically active during early part of gestation as this bat does not exhibit phenomenon of delayed embryonic development. This species of bat is continuous breeder and breeds throughout the year in Nagpur, India, (Gopalakrishna 1955). The concentration of $\mathrm{T}_{3}$ and $\mathrm{T}_{4}$ gradually declines towards the end of second pregnancy in T. longimanus (Singh et al. 2002). Thyroid gland of $T$. longimanus contains large follicles lined by squamous epithelial cells with poorly defined cell organelles suggesting less active follicular cells and decline in synthesis of thyroid hormones at the end of pregnancy supporting the above observations.

Reports of pregnancy associated changes in plasma $T_{4}$ have yielded conflicting findings. 
Increased circulating $\mathrm{T}_{4}$ levels during late pregnancy were observed in $M$. waterhousii (Burn et al. 1972). In contrast, M. lucifugus females showed lowest circulating $\mathrm{T}_{4}$ during the last half of pregnancy (Kwiecinski et al. 1991). In E. franqueti (Ifuta et al. 1988) plasma $T_{4}$ levels did not change during pregnancy. In $T$. longimanus, plasma $\mathrm{T}_{4}$ levels showed changes during pregnancy (Singh et al. 2002). Thus, in bats, increases in plasma thyroid hormone concentrations are not consistently associated with the physiological state of pregnancy but instead reflect seasonal changes that are coincident with pregnancy. In T. longimanus the ultrastructural characteristics of follicular cells indicate high synthetic activity during pregnancy. However, synthetic activity of the follicular cells declined towards the end of the pregnancy supporting the above observations.

The thyroid gland has long been recognized as an important modulator of reproductive function. Both hyper- and hypothyroidism are associated with reproductive-dysfunction and infertility. Direct effects of thyroid hormones on cellular metabolism and hormone responsiveness have been demonstrated in gonads and the sex accessory organs. Little is known about the exact manner in which thyroid hormones influence reproductive processes. Some of the impairments may be consequent upon disturbances in protein metabolism. Others may be attributed to pituitary malfunctions. In the hypophysectomized animal, thyroxine increases the rate of oxygen consumption, accelerates the heart rate etc., but does not restored normal body growth, adrenocortical growth or reproductive development. These facts suggest that thyroid hormones exert some control over the release of the hypophysial hormones like somatotrophins, corticotrophins and gonadotrophins (Kwiecinski and Damassa 2000).

The embryonic growth and pregnancy was effected by the level of thyroid hormone (Burns et al. 1972, Racey 1982). Singh et al. (2002) reported that the $\mathrm{T}_{3}$ and $\mathrm{T}_{4}$ concentration declined during the early stages of first pregnancy. However, no such change in $T_{3}$ and $T_{4}$ concentration was noticed during early stages of second pregnancy. This might be a reason for the delayed embryonic development in T. longimanus (Singh et al. 2002).

The role of the thyroid gland in reproduction is more baffling than any other gland studied so far. In T. longimanus, thyroid follicular cells are examined by light and electron microscopy and it was observed that these follicular cells are metabolically active during breeding period, pregnancy and lactation. The increased activity of cell's secretory apparatus during pregnancy could be related to development of embryo, when the demand for thyroid hormone is maximal. T. longimanus at Nagpur is a continuous breeder, pregnancies follow in a quick succession. The picture of 2 sides of genitalia during pregnancy is different. In one of the ovaries, corpus luteum of pregnancy is present and uterine horn shows graded development of embryo and the other ovary shows folliculogenesis and follicles up to Graafian follicle are observed at late pregnancy. Thus, thyroid hormones secreted by thyroid gland of estrus and pregnant bat of this species acting directly or by metabolic effects may be influcing reproductive processes in Taphozous, which is a continuous breeder.

\section{Acknowledgements}

The electron microscopy facilities provided by Dr. Arun Chitale, Department of Histopathology, Jaslok Hospital and Research Centre, Mumbai, are gratefully acknowledged. Our thanks are due to Mr. Dilip Kanaskar and Shivaji Bhosale for their excellent technical assistance.

\section{References}

Azzali, G. 1964. Ultrastructure des cellules parafolliculaires de la thyroid chez quelques mammiferes. Ann. Endocrinol. (Paris) 35: 8-22.

Abdel- Magied, E., Taha, A. and Abdalla, A. 2000. Light and Electron microscopic study of the thyroid gland of the camel (Camelus dromedarius). Anat Histol Embryol 29: 331.

Atoji, Y., Yamamoto, Y., Suzuki, Y. and Sayed, R. 1999. Ultrastructure of the thyroid gland of the one-humped camel 
(Camelus dromedarius). Anat Histol Embryol 28: 23-26.

Boswell, T., Woods, S. and Kenagy, G. 1994. Seasonal changes in body mass, insulin and glucocorticoids of free-living Golden-Mantled Ground Squirrels. Gen. Comp. Endocrinol. 96: 339-346.

Brightman, M. and Reese, T. 1969. Junction between immediately opposed cell membrane in the vertebrate brain. J. Cell Biol. 40: 648-667.

Burns, J., Baker, R. and Bleier, W. 1972. Hormonal control of delayed development in Macrotus waterhousii, 1 changes in plasma thyroxine during pregnancy and lactation. Gen. Comp. Endocrinol. 18: 54-58.

Fakuda, H., Ohsima, K., Masatoma, I. and Freor, M. 1980. Sequential changes in the pituitary-thyroid axis during pregnancy and lactation in the rat. Endocrinology 107: 1711-1716.

Fujita, H. 1971. Some observations on the fine structure of thyroid of hibernating and aroused bats. Z. Zellforsch Mikrosk Anat 121: 301-318.

Gopalakrishna, A. 1955. Observations on the breeding habits and ovarian cycle in the Indian sheath tailed bat, Taphozous longimanus (Hardwicke). Proc Indian Natl Sci Acad 21 (B): 29-41.

Ifuta, N., Gevaerts, H. and Kuhn, E. 1988. Thyroid hormones, testosterone and estradiol-17- $\beta$ in plasma of Epomops franqueti (Tomes 1860) (Chiroptera) in the rain forest of the equator. Gen. Comp. Enodocrinol. 69: 378-380.

Jannini, E., Ulisse, S. and D'armiento, M. 1995. Thyroid hormone and male gonadal function. Endocr. Rev. 16: 443-459.

Khurana, M. and Madan, M. 1986. Effect of state of pregnancy on circulating thyroidal hormones among Karn Swiss and Murrah animals. Indian Journal of Dairy Science 39: 128-132.

Krishna, A. and Dominic, C. 1982a. Differential rates of fetal growth in two successive pregnancies in the emballonurid bat, Taphozous longimanus (Hardwicke). Bio Reprod. 27: 351-353.

Krupp, P., Young, R. and Frink, R. 1977. The thyroid gland of the woodchuck, Marmota monax: A morphological study of seasonal variations in the follicular cells. Anat. Rec. 187: 495-514.

Kwiecinski, G. and Damassa, D. 2000. Peripheral endocrines in bat reproduction: thyroid gland, Reproductive Biology of Bats, Academic Press, San Diego. pp. 67-72.

_, - - and Gustafson, A. 1991. Patterns of plasma sex-hormone-binding globulin, thyroxine and thyroxine-binding globulin in relation to reproduction in female little brown bats. J. Endocrinol. 128: 63-70.

- Wimsatt, W. and Krrok, L. 1987b. Morphology of thyroid C-cell and parathyroid glands in summer- active little brown bats, Myotis lucifugus lucifugus with particular reference to pregnancy and lactation. Am. J. Anat. 178: 421-427.

Loewenstein, J. and Wollman, S. 1967. Diffusion of thyroglobulin in the lumen of rat thyroid follicle. Endocrinology 81: 1086-1090.

Mayant, N. 1964. The thyroid gland, (eds.) River and Trotter Vol. 1, pp. 283-297.

Nunez, E. A. and Becker, D. 1970. Secretory processes in follicular cells of the bat thyroid. I. Ultrastructural changes during the pre-, early and mid- hibernation periods with some comments on the origin of autophagic vacuoles. Am. J. Anat. 129: 369-398.

- 1971. Secretory processes in follicular cells of the bat thyroid II. The occurrence of organelle-associated intercellular junctions during late hibernation. Am. J. Anat. 13: 227-239.

- Wallis, J. and Gershon, M. 1974. Secretory processes in follicular cells of the bat thyroid. III. The occurrence of extracellular vesicles and colloid droplets during arousal from hibernation. Am. J. Anat. 141: 179-202.

Racey, P. 1982. Ecology of bat reproduction. In: Ecology of Bats, (ed.) T. H. Kunz, Plenum Press, New York, pp. 57-164.

Sadler, W. and Tyler, W. 1960a. Thyroidal activity in hibernating chiroptera. I. Uptake of (131)-I. Acta Endocrinol. 34: 586-596.

— and Tyler, W. 1960b. Thyroidal activity in hibernating chiroptera. II. Synthesis of radio-iodinated amino acids. Acta Endocrinol. 34: 597-604.

Seljelid, R. 1967. Endocytosis in thyroid follicle cells. III. An electron microscopic study of the cell surface and related structures. J. Ultrastruct. Res. 18: 1-18.

Seraphim, E. 2004. Endocrine interaction during different phases of the female reproductive cycle in Hipposideros lankadiva (Kelaart). Ph.D. thesis, RTM Nagpur Uni., Nagpur.

Singh, U., Krishna, A. and Bhatnagar, K. 2002. Seasonal changes in thyroid activity in the female sheath tailed bat, Taphozous longimanus (Chiroptera: Emballonuridae). Acta Biol. Hung. 53: 267-278.

Shimokawa, T., Nakanishi, Hondo, E., Iwasaki, T., Kiso, Y. and Makita, T. 2002. A morphological study of the thyroid gland in Risso's dolphin, Grampus griseus. J. Vet. Med. Sci. 64: 509-512.

Velicky, J. and Titlbach, M. 1972. A study of the bat thyroid gland in winter and early spring. II. Electron microscopic observations. Folia. Morphol. (Praha) 20: 406-415.

- and - 1974. Electron microscopic observations in the thyroid gland of active bats. Z Mikrosk Anat Forsch 88: 1069-1092.

Wollman, S. 1969. Secretion of thyroid hormones. In: J. T. Dingle and H. B. Fell, (eds.) Lysosomes in Biology and Pathology. Vol. 2 Capt. 17, North Holland Publishing, Amsterdam. pp. 483-512. 